\title{
Pendekatan Etnofarmasi Tumbuhan Obat Imunomodulator Suku Tengger Desa Ngadas, Kabupaten Malang, Indonesia
}

\author{
Weka Sidha Bhagawan ${ }^{1 *}$, Yaya Sulthon Aziz ${ }^{2}$, Rizki Putra Teguh Pamungkas ${ }^{3}$
}

\author{
${ }^{1}$ Departemen Farmasi, Fakultas Ilmu Kesehatan, Universitas PGRI Madiun, Jl. Setia Budi No. 85 Madiun Indonesia \\ ${ }^{2}$ Departemen Farmasi, Akafarma Sunan Giri, Jl. Batoro Katong No. 32 Ponorogo Indonesia \\ ${ }^{3}$ Departemen Farmasi, Fakultas Farmasi, Universitas Jember, Jl. Kalimantan 1 No. 2 Jember Indonesia
}

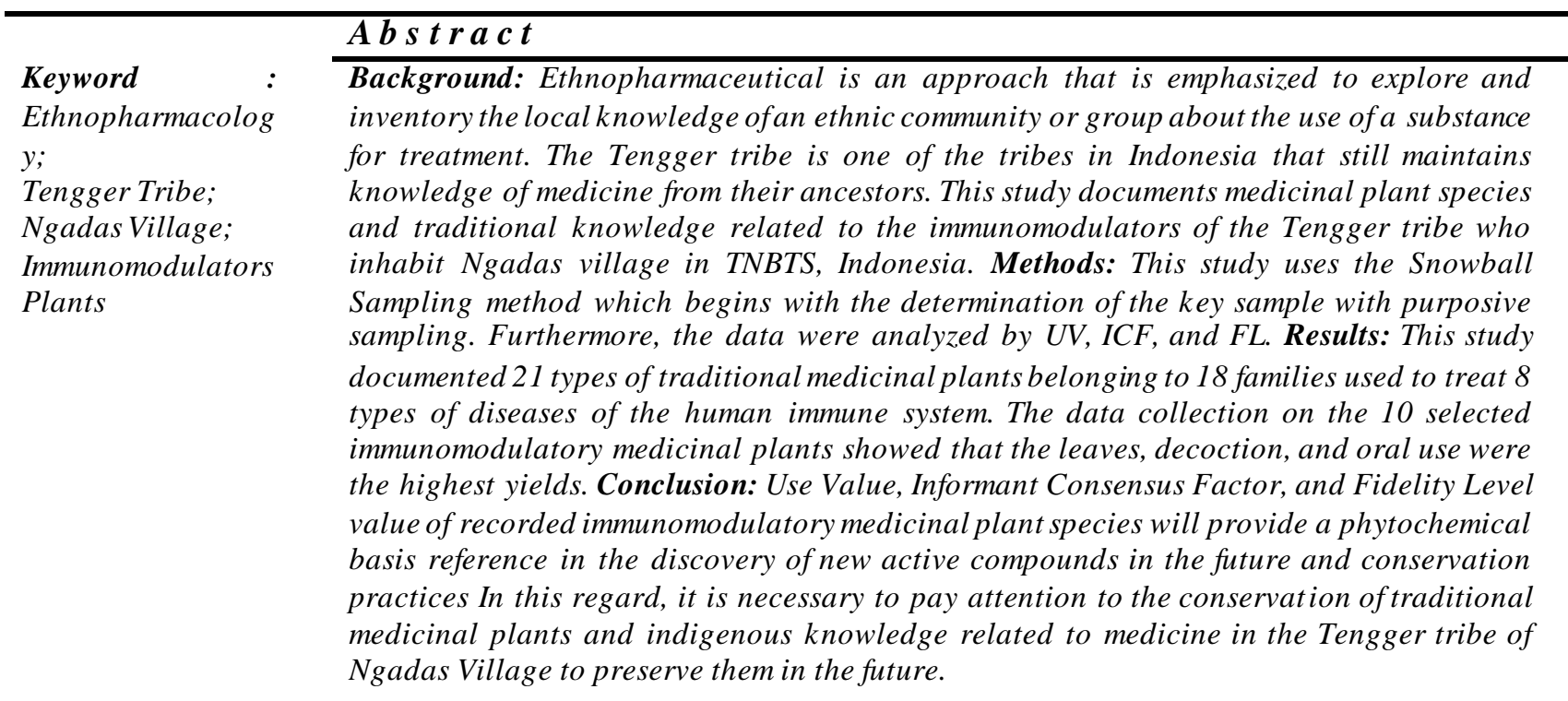

\begin{tabular}{ll}
\hline Kata kunci: & A B S T R A K \\
\cline { 2 - 3 } Desa Ngadas; & Latar belakang: Etnofarmasi merupakan pendekatan yang ditekankan untuk menggali serta \\
Etnofarmasi; & menginventarisasi pengetahuan lokal masyarakat suatu etnis atau kelompok tentang \\
Suku Tengger; & penggunaan suatu bahan untuk pengobatan. Suku tengger merupakan salah satu suku di \\
Tumbuhan & Indonesia yang masih mempertahankan pengetahuan pengobatan dari leluhur. Studi ini \\
Imunomodulator & mendokumentasikan spesies tanaman obat dan pengetahuan tradisional yang terkait \\
& imunomodulator masyarakat suku Tengger yang mendiami desa Ngadas di TNBTS, \\
& Indonesia. Metode: Penelitian ini menggunakan metode Snowball Sampling yang diawali \\
& dengan penetuan sampel kunci dengan Purposive Sampling. Selanjutnya data dianalisa \\
& dengan UV, ICF, dan FL. Hasil: Studi ini mendokumentasikan 21 jenis tumbuhan obat \\
& tradisional yang tergolong dalam 18 famili yang digunakan untuk mengobati 8 jenis penyakit \\
& sistem imun manusia. Pendataan 10 tumbuhan obat imunomodulator terpilih menunjukkan \\
& bahwa bagian daun, pembuatan secara dekokta, dan penggunaan secara diminum merupakan \\
& hasil terbanyak. Kesimpulan: Nilai Use Value, Informant Consensus Factor, dan nilai \\
& Fidelity Level dari spesies tanaman obat imunomodulator yang tercatat akan memberikan \\
& reverensi dasar secara fitokimia dalam penemuan senyawa aktif baru di masa depan serta \\
& praktik konservasi. Sehubungan dengan hal tersebut, perlu diperhatikan konservasi tanaman \\
& obat tradisional dan pengetahuan asli terkait pengobatan di wilayah suku Tengger Desa \\
& Ngadas untuk melestarikannya di masa depan.
\end{tabular}

*Corresponding author

Email: weka.sidha@unipma.ac.id 


\section{PENDAHULUAN}

Masyarakat memiliki sejarah panjang tentang penggunaan tumbuhan obat tradisional untuk tujuan medis di dunia, dan sekarang ini sangat gencar dipromosikan. Interaksi antara manusia dan tumbuhan telah lama dideskripsikan sebagai salah satu faktor yang mempengaruhi peradaban manusia, khususnya dalam bidang pengobatan (1). Dokumentasi penggunaan tumbuhan obat melalui studi etnofarmasi memungkinkan pengembangan obat dan perawatan kontemporer serta untuk konservasi tanaman (2-4).

Banyak studi etnofarmasi di seluruh dunia, termasuk di Indonesia, melaporkan penggunaan tanaman herbal untuk proses penyembuhan, yang telah digunakan selama beberapa generasi di masyarakat masing-masing (5,6). Etnofarmasi merupakan pendekatan yang ditekankan untuk menggali serta menginventarisasi pengetahuan lokal masyarakat suatu etnis atau kelompok tentang penggunaan suatu bahan untuk pengobatan (2). Meskipun keanekaragaman budaya di Indonesia berkontribusi pada luasnya pengetahuan tradisional ini (7), aksesnya sangat terbatas. Pengetahuan tradisional biasanya diturunkan secara lisan dan seringkali bersifat spesifik. Oleh karena itu, pengetahuan tersebut seringkali dimiliki oleh para pemimpin suku, kepala desa, sesepuh, atau dukun tradisional pada komunitas atau suku tertentu (8).

Suku tengger merupakan salah satu suku di Indonesia yang masih mempertahankan pengetahuan pengobatan dari leluhur. Masyarakat suku Tengger terdistrtibusi dan menyebar pada beberapan desa, salah satunya adalah Desa Ngadas Kecamatan Poncokusumo Kabupaten Malang (9). Pada kehidupan sehari-hari masyarakat suku Tengger di Desa Ngadas memanfaatkan tumbuhan yang hidup di sekitar Taman Nasional Bromo Tengger Semeru (TNBTS) untuk diperdagangkan dan dimanfaatkan sebagai kebutuhan pribadi. Selain itu, tumbuhan spesifik juga digunakan untuk tujuan tertentu seperti upacara suku dan penggunaan untuk obat. Desa Ngadas berlokasi pada ketinggian 2150 mdpl dengan luas area sekitar 395 ha dengan topografi berbukit, sehingga mempunyai suhu dan kelembaban rendah (10). Hal tersebut menjadikan pemanfaatan tumbuhan obat untuk meningkatkan sistem imun (imunomodulator) oleh masyarakat suku Tengger Desa Ngadas menjadi tinggi.

Masyarakat Tengger menggunakan tanaman dari TNBTS untuk upacara adat (11), serta aplikasi obat (12), bahan industri, sumber makanan, dan bahan bangunan di beberapa wilayah desa (13). Namun, tidak ada laporan mengenai aspek ethnofarmasi dari tanaman obat yang digunakan untuk imunomodulator di wilayah desa Ngadas oleh masyarakat Tengger. Studi ini mendokumentasikan spesies tanaman obat dan pengetahuan tradisional yang terkait imunomodulator masyarakat suku Tengger yang mendiami desa Ngadas di TNBTS, Indonesia.

\section{METODE}

\section{Studi Area}

Penelitian ini dilakukan di Desa Ngadas yang secara administratif masuk dalam wilayah Kecamatan Poncokusumo Kabupaten Malang, Indonesia. Terletak di sekitar Taman Nasional Bromo Tengger Semeru (TNBTS) (Gambar. 1). Desa Ngadas terletak di ketinggian 2.150 mdpl. Total area penelitian terdiri dari $414 \mathrm{~km} 2$. Seperti daerah lain di Indonesia, Desa Ngadas hanya memiliki dua musim; kemarau dan hujan. Musim hujan berlangsung pada bulan November-Mei, sedangkan musim kemarau berlangsung pada bulan Juni-Oktober. Sebagian besar penduduknya berasal dari suku Tengger dan mengandalkan pertanian. Desa Ngadas berpenduduk 1.909 jiwa, terdiri dari 988 laki-laki dan 921 perempuan (10).

\section{Koleksi Data}


Koleksi data diperoleh melalui wawancara semi terstruktur dan terstruktur dengan informan yang mengetahui atau memanfaatkan tumbuhan sebagai obat. Teknik ini biasanya digunakan dalam studi ethnofarmasi (15). Wawancara dilakukan untuk mengetahui dan menggali pengetahuan tradisional mengenai pemanfaatan jenis tumbuhan obat, kegunaannya, bagian yang dimanfaatkan, cara penyiapan dan cara penggunaannya. Kegiatan wawancara dilakukan secara utuh dengan menggunakan kuesioner. Pemilihan informan berdasarkan tehnik Snowball Sampling, dengan menentukan informan kunci di awal (dukun adat desa dan kepala desa) menggunakan tehnik Purposive Sampling. Informan kunci adalah orang yang memiliki pengaruh yang kuat di dalam masyarakat mengetahui kearifan local dari leluhur. Informan selanjutnya ditentukan oleh arahan responden sebelumnya (16).

\section{Determinasi Tumbuhan}

Sampel tumbuhan diambil dengan menggunakan tehnik herbarium. Selanjutnya tumbuhan yang telah dilakukan tehnik herbarium dideterminasi nama spesies dan famili oleh Herbarium Jemberiense, Jember, Indonesia.

\section{Klasifikasi dan Pengelompokan Penyakit Imun}

\begin{abstract}
Pengelompokan dan klasifikasi penyakit terkait sistem imun dikelompokkan berdasarkan penyakit yang lazim terjadi di wilayah Indonesia. Penyakit imunomodulator tersebut antara lain: masuk angina, perut kembung, batuk, nyeri persendian, pusing, lemah syahwat (afrodisiak), dan demam.
\end{abstract}

\section{Analisis Data}

Penyakit terkait sistem imun yang dicatat dalam penelitian ini dikelompokkan menjadi delapan kategori. Informant Consensus Factor (ICF) dihitung untuk menentukan efektivitas tanaman obat dalam setiap kategori penyakit menurut Heinrich et al. (1998). ICF dihitung dengan rumus: $\mathrm{ICF}=$ Nur $-\mathrm{Nt} / \mathrm{Nur}-1$, dimana Nur mengacu pada jumlah laporan penggunaan untuk kategori penyakit tertentu dan $\mathrm{Nt}$ mengacu pada jumlah spesies tanaman obat yang digunakan untuk kategori penyakit tertentu oleh semua informan (17).

Di sisi lain berdasarkan Phillips et al. (1994), Use Value (UV) juga dihitung untuk melihat kepentingan relatif masingmasing jenis tanaman obat tradisional untuk pengobatan penyakit di wilayah studi. UV dihitung dengan rumus UV = $\Sigma$ Ui / n dimana UV adalah total nilai pakai spesies tanaman obat tradisional,

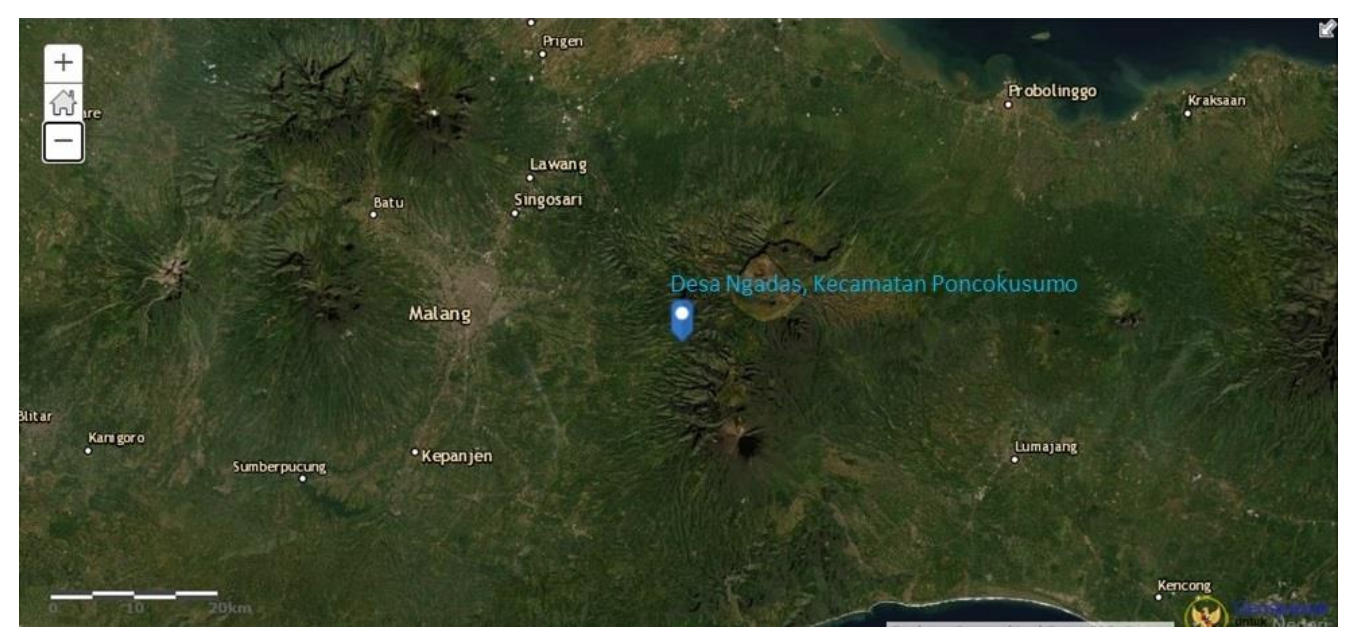

Gambar 1. Lokasi Desa Ngadas Kecamatan Poncokusumo (14) 
sedangkan $\Sigma$ Ui mengacu pada banyaknya laporan penggunaan yang dikutip oleh masing-masing informan untuk spesies tanaman tertentu dan $\mathrm{n}$ adalah jumlah total. informan yang diwawancarai untuk spesies tumbuhan tertentu (18).

Fidelity level (FL) dihitung untuk menentukan nilai dari spesies tanaman yang paling sering digunakan untuk mengobati penyakit tertentu menurut Friedman et al. (1986). Nilai ini dihitung dengan rumus $\mathrm{FL}=\mathrm{Np} / \mathrm{N}$ di mana $\mathrm{Np}$ adalah jumlah laporan penggunaan yang dikutip untuk spesies tertentu untuk penyakit tertentu dan $\mathrm{N}$ mengacu pada jumlah total laporan penggunaan yang dikutip untuk spesies tanaman obat tradisional tertentu (19).

\section{HASIL}

\section{Jenis Tumbuhan Obat yang Diperoleh}

Studi ini mendokumentasikan 21 jenis tumbuhan obat tradisional yang tergolong dalam 18 famili yang digunakan untuk mengobati 8 jenis penyakit system imun manusia. Famili tumbuhan Apiaceae, Asteraceae, Rosaceae, Rubiaceae, Solanaceae, dan Zingiberaceae menyumbang jumlah jenis tumbuhan obat masing-masing 2. Famili Poaceae, Clusiaceae, Bacellaceae, Acoraceae, Usneaceae, Myrtaceae, Piperaceae, Fabaceae, Apocynaceae, dan Plantaginaceae dengan masing-masing satu jenis tumbuhan.

\section{Informant Consensus Factor}

Penyakit system imun di wilayah
studi dikelompokkan menjadi tujuh kategori penyakit dan kemudian analisis Informant Consensus Factor (ICF) dihitung. Didapatkan hasil, penyakit batuk mencetak nilai ICF tertinggi (0.75) diikuti oleh penyakit nyeri persendian (0.72) (Tabel 1). Penyakit batuk juga menjadi masalah kesehatan terbanyak di Desa Ngadas.

Tabel 1. Nilai Informant Consensus Factor (ICF) dari 7 kategori penyakit sistem imun

\begin{tabular}{cll}
\hline No. & Jenis Penyakit Imun & ICF \\
\hline 1. & Batuk & 0.75 \\
2. & Nyeri persendian & 0.72 \\
3. & Lemah & 0.67 \\
& (Afrodisiak) & \\
4. & Demam & 0.57 \\
5. & Perut kembung & 0.57 \\
6. & Masuk angina & 0.50 \\
7. & Pusing & 0.50 \\
\hline
\end{tabular}

Penyakit batuk biasanya diatasi dengan menggunakan Foeniculum vulgare Miller, sedangkan nyeri persendian diobati dengan Bidens pilosa L. dan Borreria laevis Griseb.

\section{Use Value}

Hasil penghitungan use value (UV) pada tabel 2 menunjukkan bahwa Foeniculum vulgare Miller dan Bidens pilosa L. memiliki nilai tertinggi, yaitu 1 memiliki nilai guna yang lebih tinggi dibandingkan spesies lainnya.

\section{Fidelity Level}

Penghitungan fidelity level (FL) pada tabel 2 dilakukan untuk jenis tanaman obat imunomodulator yang paling banyak dikutip dengan sembilan informan ke atas. Hasil perhitungan menunjukkan bahwa semua memiliki nilai lebih dari 0,5 (Tabel 2). Dari hasil tersebut, Foeniculum vulgare Miller dan Bidens pilosa L. mendapatkan nilai FL tertinggi berturut-turut yaitu 0,95 dan 0,86 .

\section{Bagian, Pembuatan, dan Penggunaan Tumbuhan Obat Terpilih}

Hasil pendataan 10 tumbuhan obat imunomodulator pada tabel 3 terpilih menunjukkan bahwa bagian daun, herba, buah, dan rimpang serta biji merupakan bagian tumbuhan yang digunakan untuk 
Tabel 2. Nilai Use Value (UV) dan Fidelity Level (FL) dari 10 tumbuhan obat imunomodulator yang paling banyak dirujuk

\begin{tabular}{|c|c|c|c|c|c|c|c|}
\hline No. & Nama Spesies & Nama Lokal & Khasiat & UV & $\mathbf{N}$ & $\mathbf{N p}$ & FL \\
\hline 1. & Foeniculum vulgare Miller & Adas & Batuk & 1 & 21 & 20 & 0.95 \\
\hline 2. & Bidens pilosa $\mathrm{L}$. & Sempretan & Nyeri persendian & 1 & 21 & 18 & 0.86 \\
\hline 3. & Bidens pilosa $\mathrm{L}$. & Sempretan & Afrodisiak & 1 & 21 & 16 & 0.76 \\
\hline 4. & Borreria laevis Griseb. & Tepung Otot & Nyeri persendian & 0.57 & 12 & 9 & 0.75 \\
\hline 5. & Prunus persica L. Batch. & Jambu Wer & Perut kembung & 0.57 & 12 & 8 & 0.67 \\
\hline 6. & Prunus persica L. Batch. & Jambu Wer & Masuk angina & 0.57 & 12 & 8 & 0.67 \\
\hline 7. & Acorus calamus L. & Dringu & Demam & 0.43 & 9 & 5 & 0.56 \\
\hline 8. & Pimpinella pruatjan Molk. & Jahe Wono & Afrodisiak & 0.52 & 11 & 6 & 0.55 \\
\hline 9. & Plantago major $\mathrm{L}$ & Sri Pandak & Perut kembung & 0.38 & 14 & 7 & 0.50 \\
\hline 10. & Alyxia reinwardtii $\mathrm{Bl}$. & Pulosari & Masuk angina & 0.48 & 12 & 6 & 0.50 \\
\hline
\end{tabular}

Tabel 3. Bagian, cara pembuatan, dan cara penggunaan tumbuhan obat imunomodulator terpilih

\begin{tabular}{clcccc}
\hline No. & Nama Spesies & Khasiat & Bagian & Pembuatan & Penggunaan \\
\hline 1. & Foeniculum vulgare Miller & Batuk & Daun dan Biji & Dekokta & Diminum \\
2. & Bidens pilosa L. & Nyeri persendian & Herba & Dekokta & Diminum \\
3. & Bidens pilosa L. & Afrodisiak & Herba & Dekokta & Diminum \\
4. & Borreria laevis Griseb. & Nyeri persendian & Herba & Ditumbuk halus & Dioleskan \\
5. & Prunus persica L. Batch. & Perut kembung & Buah muda & Dekokta & Diminum \\
6. & Prunus persica L. Batch. & Masuk angina & Buah muda & Dekokta & Diminum \\
7. & Acorus calamus L. & Demam & Daun muda & Ditumbuk halus & Dioleskan \\
8. & Pimpinella pruatjan Molk. & Afrodisiak & Rimpang & Dekokta & Diminum \\
9. & Plantago major L. & Perut kembung & Daun & Dekokta & Diminum \\
10. & Alyxia reinwardtii Bl. & Masuk angina & Daun & Dekokta & Diminum \\
\hline
\end{tabular}

pengobatan. Terdapat 2 macam cara pembuatan yang didapatkan dari 10 jenis tumbuhan imunomodulator terpilh, yaitu diseduh dengan menggunakan air (dekokta) dan ditumbuk halus. Sebagian besar cara penggunaan tumbuhan obat imunomodulator yaitu diminum dan sisanya dioleskan pada bagian tubuh tertentu.

\section{PEMBAHASAN}

Alasan ditemukannya sejumlah besar spesies tumbuhan obat tradisional imunomodulator yang terdokumentasi dan pemanfaatan masyarakat suku Tengger di Desa Ngadas dapat dikaitkan dengan kondisi cuaca yang dingin sehingga kebutuhan akan obat imunomodulator relatif tinggi. Dengan demikian, keberadaan berbagai jenis tumbuhan imunomodulator di Desa Ngadas dapat menjadi sumber kearifan lokal yang berharga yang digunakan masyarakat. Hal ini dapat dikaitkan dengan fakta bahwa obat-obatan herbal tradisional telah membantu masyarakat untuk merasa aman dengan pengobatan asli mereka yang mungkin juga hemat biaya (5).

Berdasarkan hasil koleksi tumbuhan obat imunomodulator tersebut, yang menyebutkan keberaneka ragaman famili tumbuhan yang terdapat di Desa Ngadas dapat dikaitkan dengan keaneka ragaman hayati di TNBTS sangatlah tinggi, sesuai dengan penelitian terdahulu di wilayah yang sama $(12,20)$. Di antara total spesies tanaman obat imunomodulator yang terdokumentasi, Bidens pilosa L dan Prunus persica L. Batch digunakan untuk mengobati jumlah penyakit sistem imun terbanyak, yaitu 2 penyakit. Dari total spesies tanaman obat imunomodulator yang dikumpulkan, sebagian besar ditemukan di alam liar sisanya diperoleh dari pekarangan rumah (yang dibudidayakan di rumah, digunakan juga 
sebagai makanan atau murni untuk pengobatan atau keduanya). Lokasi konservasi spesifik untuk spesies tanaman obat sudah sangat jelas ditetapkan di wilayah studi ini, yaitu Taman Nasional Bromo Tengger Semeru.

Bagian daun paling banyak digunakan untuk pengobatan sistem imun di suku Tengger Desa Ngadas. Daun merupakan bagian tumbuhan yang umum digunakan dalam pengobatan tradisional di Indonesia $(12,20,21)$ dan dunia (22-24). Selain penyiapan yang mudah, bagian daun kurang berdampak terhadap proses hidup tumbuhan jika dimanfaatkan sebagai bahan obat tradisional, jika dibandingkan dengan bagian akar atau batang, sehingga kelestarian tumbuhan obat dapat terjaga.

Pembuatan atau preparasi tumbuhan obat imunomodulator pada suku Tengger Desa Ngadas sebagian besar dilakukan dengan dekokta. Preparasi secara dekokta lazim digunakan pada penyiapan obat tradisional di wilayah asia tenggara (25). Sedangkan penggunaan tumbuhan obat tradisional imunomodulator sebagian besar diminum dengan dosis dan jangka waktu tertentu. Pengetahuan lokal pengobatan tradisional suku Tengger Desa Ngadas khususnya dan masyarakat suku Tengger keseluruhan pada umumnya harus dilestarikan dan dijaga. Karena sangat rentan terkena dampak modernisasi dari luar (7). Meskipun demikian, suku ini masih menjaga kearifan lokal pengobatan tradisional mereka sehingga dapat dijadikan referensi ditemukannya senywa berkhasiat obat baru dan konservasi tumbuhan obat dapat berlanjut.

\section{KESIMPULAN}

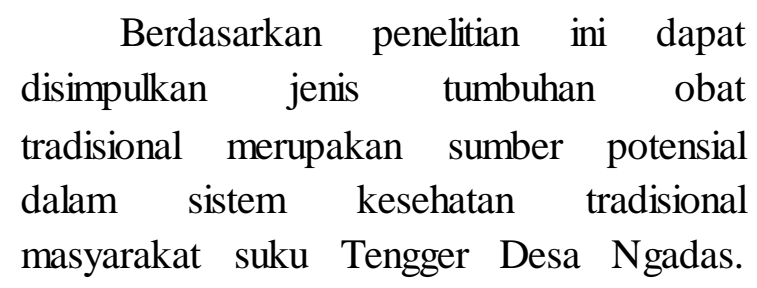

Studi menegaskan bahwa masyarakat telah menggunakan spesies tumbuhan obat imunomodulator dan pengetahuan lokal terkait pengobatan sistem imun sebagai pilihan utama meskipun layanan kesehatan modern berkembang di wilayah tersebut.

Nilai Use Value, Informant Consensus Factor, dan nilai Fidelity Level dari spesies tanaman obat imunomodulator yang tercatat akan memberikan reverensi dasar secara fitokimia dalam penemuan senyawa aktif baru di masa depan serta praktik konservasi. Sehubungan dengan hal tersebut, perlu diperhatikan konservasi tanaman obat tradisional dan pengetahuan asli terkait pengobatan di wilayah suku Tengger Desa Ngadas untuk melestarikannya di masa depan.

\section{UCAPAN TERIMA KASIH}

Ucapan terimakasih diberikan kepada seluruh masyarakat suku Tengger Desa Ngadas yang telah membantu sepenuh hati dalam penelitian ini "Hong Ulun Basuki Langgeng". Terimakasih diucapkan pula kepada UKM Pring Kuning, Farmasi Universitas Jember atas proses yang selama ini dilewati terkait dengan Etnofarmasi "Rumpun Bambu Terkuat Tumbuh di Atas Tanah yang Keras".

\section{DAFTAR PUSTAKA}

1. Yeung AWK, Heinrich M, Kijjoa A, Tzvetkov NT, Atanasov AG. The ethnopharmacological literature: An analysis of the scientific landscape. J Ethnopharmacol [Internet]. 2020 Mar;250:112414. Available from: https://linkinghub.elsevier.com/retriev e/pii/S0378874119311225

2. Heinrich M. Ethnopharmacology in the 21st century - grand challenges. Front Pharmacol. 2010;(June):1980-2.

3. Heinrich M. Ethnobotany and its role 
in drug development. Phyther Res [Internet]. 2000 Nov;14(7):479-88. Available from: https://onlinelibrary.wiley.com/doi/10.

1002/1099-

1573(200011)14:7\%3C479::AID-

PTR958\%3E3.0.CO;2-2

4. Calzada F, Bautista E. Plants used for the treatment of diarrhoea from Mexican flora with amoebicidal and giadicidal activity, and their phytochemical constituents. J Ethnopharmacol [Internet]. 2020 May;253:112676. Available from: https://linkinghub.elsevier.com/retriev e/pii/S0378874119337092

5. Elfahmi, Woerdenbag HJ, Kayser O. Jamu: Indonesian traditional herbal medicine towards rational phytopharmacological use. J Herb Med [Internet]. 2014 Jun;4(2):51-73. Available from: https://inkinghub.elsevier.com/retriev e/pii/S2210803314000049

6. Sujarwo W, Keim AP, Savo V, Guarrera PM, Caneva G. Ethnobotanical study of Loloh: Traditional herbal drinks from Bali (Indonesia). J Ethnopharmacol [Internet]. 2015;169(January):34-48. Available from: http://dx.doi.org/10.1016/j.jep.2015.03 .079

7. Sujarwo W, Arinasa IBK, Salomone F, Caneva G, Fattorini S. Cultural Erosion of Balinese Indigenous Knowledge of Food and Nutraceutical Plants. Econ Bot [Internet]. 2014 Dec 18;68(4):426-37. Available from: http://link.springer.com/10.1007/s122 31-014-9288-1

8. Supiandi MI, Mahanal S, Zubaidah S, Julung $H$, Ege B. Ethnobotany of traditional medicinal plants used by Dayak Desa Community in Sintang, West Kalimantan, Indonesia. Biodiversitas J Biol Divers [Internet]. 2019 Apr 19;20(5):1264-70. Available from: https://smujo.id/biodiv/article/view/35
05

9. Sutarto A. Sekilas Tentang Masyarakat Tengger. In: Pembekalan Jelajah Budaya, Balai Kajian Sejarah dan Nilai Tradisional. Yogyakarta; 2006. p. 1-15.

10. Badan Pusat Statistik. Kecamatan Poncokusumo Dalam Angka. Malang; 2019.

11. Batoro J, Hakim L, Rahardi B. Traditional Knowledge Sacred Area: Holly Sites ( Pedanyangan ) in Tengger Tribe of East Java , Indonesia. Adv Life Sci. 2019;9(1):16.

12. Bhagawan WS. Etnofarmasi Suku Tengger Kecamatan Senduro Kabupaten Lumajang [Internet]. Jember University; 2011. Available from:

http://repository.unej.ac.id/handle/123 456789/26574

13. Rohman F, Lestari SR, Utomo DH, Purwanto, Juma Y, Arifah SN, et al. The Utilization of Plant Diversity by Tengger Tribe around Bromo Tengger Semeru National Park, East Java, Indonesia. In: IOP Conference Series: Earth and Environmental Science. 2019.

14. Pusat Pengelolaan dan Penyebarluasan Informasi Geospasial. Indonesia Geospasial Portal, Rupa Bumi Indonesia [Internet]. 2020. Available from: sdi.or.id/portal/home/

15. Pieroni A, Houlihan L, Ansari N, Hussain B, Aslam S. Medicinal perceptions of vegetables traditionally consumed by South-Asian migrants living in Bradford, Northern England. J Ethnopharmacol [Internet]. 2007 Aug;113(1):100-10. Available from: https://linkinghub.elsevier.com/retriev e/pii/S0378874107002437

16. Chekole G. Ethnobotanical study of medicinal plants used against human ailments in Gubalafto District, Northern Ethiopia. J Ethnobiol Ethnomed. 2017;13(1):1-29. 
17. Heinrich M, Ankli A, Frei B, Weimann C, Sticher O. Medicinal plants in Mexico: healers' consensus and cultural importance. Soc Sci Med [Internet]. 1998 Dec;47(11):1859-71. Available from: https://linkinghub.elsevier.com/retriev e/pii/S0277953698001816

18. Phillips O, Gentry A, Reynel C, Wilkin $\mathrm{P}$, Galvez-Durand $\mathrm{C}$. Quantitative etnobotany and Amazonian conservation. Conserv Biol. 1994;8(1):225-48.

19. Friedman J, Yaniv Z, Dafni A, Palewitch D. A preliminary classification of the healing potential of medicinal plants, based on a rational analysis of an ethnopharmacological field survey among Bedouins in the Negev Desert, Israel. J Ethnopharmacol [Internet]. 1986 Jun;16(2-3):275-87. Available from:

https://inkinghub.elsevier.com/retriev e/pii/0378874186900942

20. Batoro J, Siswanto D. Ethnomedicinal survey of plants used by local society in Poncokusumo district, Malang, East Java Province, Indonesia. Asian J Med Biol Res. 2017;3(2):158-67.
21. Nahdi MS, Martiwi INA, Arsyah DC. The ethnobotany of medicinal plants in supporting the family health in Turgo, Yogyakarta, Indonesia. Biodiversitas. 2016;17(2):900-6.

22. Nadiroğlu M, Behçet L, Çakılcıoğlu U. An ethnobotanical survey of medicinal plants in karlova (Bingölturkey). Indian $\mathrm{J}$ Tradit Knowl. 2019;18(1):76-87.

23. Skalli S, Hassikou R, Arahou M. An ethnobotanical survey of medicinal plants used for diabetes treatment in Rabat, Morocco. Heliyon [Internet]. 2019;5(3):e01421. Available from: https://doi.org/10.1016/j.heliyon.2019. e01421

24. Polat R. Ethnobotanical study on medicinal plants in Bingöl (City center) (Turkey). J Herb Med [Internet]. 2019 Jun;16:100211. Available from: https://inkinghub.elsevier.com/retriev e/pii/S2210803318300083

25. Nguyen TS, Xia NH, Van Chu T, Van Sam H. Ethnobotanical study on medicinal plants in traditional markets of son la province, Vietnam. For Soc. 2019;3(2):171-92. 